\title{
Board 12: Inclusive Learning and Teaching Strategies or Effective Course Design? Constructing Significant Learning Experiences in Low and High Achieving Learners
}

\section{Robert Wayne Gammon Pitman, Ohio State University}

$\mathrm{PhD}$ student in STEM education with a focus in engineering education. I am an engineering educator determined to improve student learning via effective teaching \& learning strategies, professional development, outreach, and community development.

LinkedIn URL Below https://www.linkedin.com/in/robert-gammon-pitman-5888152b

\section{Dr. Paul E. Post, Ohio State University}

Ph.D. in Industrial Technology, Purdue University M.S. in Industrial Education, Purdue University B.S. in Industrial Arts Education, Pennsylvania State University

OSU faculty member since 1984 Currently in the STEM education program

2013 International Technology and Engineering Educators Association Conference Co-Chair

Currently Executive Director and a Past-President of the Ohio Technology and Engineering Educators Association

\section{Lin Ding,}

Lin Ding, Ph.D., is an associate professor in the Department of Teaching and Learning at The Ohio State University. Dr. Ding's scholarly interests lie in discipline-based STEM education research. His work includes theoretical and empirical investigations of student content learning, problem solving, reasoning skills, and epistemological development. Dr. Ding specializes in research-based assessment development and focuses primarily on the quantitative research paradigm. He has published numerous high-impact journal articles, book chapters, and research proceedings papers. In addition, Dr. Ding has been leading multiple federal and state projects sponsored by the National Science Foundation (NSF) and the Ohio Department of Education. Also, he frequently serves as an invited editorial board member, referee or panelist for various international journals, funding agencies, and professional associations. 
Work-in-Progress: Inclusive Learning and Teaching Strategies or Effective Course Design? Constructing Significant Learning Experiences in Low and High Achieving

\section{Learners}

\section{Background}

While the percentage of Science, Technology, Engineering, and Mathematics (STEM) majors continues to decline in the United States, the ongoing shortages of under-represented groups and minorities remain for these majors and in the workforce [1-2]. Addressing diversity barriers or challenges are paramount in engineering education as racial, gender, and ethnic biases marginalize under-represented students like African Americans, students of low socio-economic status, women, and Hispanics. These negative perceptions and stereotypes of under-represented students have reportedly affected student learning and performance [3]. The lack of inclusion or having a sense of belonging can occur in the classroom from the remarks of students or instructors via student-student or student-instructor interactions. Although the instructor or a student may unintentionally state or imply stereotypes, a subtle trace can disengage underrepresented students possibly causing them to change majors. Certain instructional strategies may remove stereotypes by creating an inclusive learning environment. While the instructor initiates these strategies, it is through the joint-actions of students and teacher(s) to establish and sustain the classroom environment. One way these actions can be indicators of broadening participation in under-represented groups is through The National Science Foundation's (NSF) framework proposes indicators of Diversity and Inclusion which can be short- or long-term changes of under-represented student outcomes at the institutional and individual level [4]. At the individual level, the indicators are intellectual and social participation with peers, retention, persistence, student experiences in successfully completing courses, and attitudes like confidence in abilities). Measures of individual factors like class participation, confidence in abilities, and performance on course assignments are shaped by the instructor's teaching strategies.

Although traditional instructional practices are prominent in science, technology, engineering, and mathematics (STEM) undergraduate courses, such as lecturing, [5], students in activelearning instruction have been reported to perform better than students from traditional instruction[5]. Traditional lecturing has been reported as less effective for student learning because students are passive participants with minimal opportunity to interact and participate with instructor [6-7]. Over time, the continuous passive engagement and lack of participation are less effective for student learning versus students having a more active participatory role in purposeful activities [8].

Student engagement and their perceptions of effective instructional activities have been positively correlated with achievement (GPA), critical thinking, and retention of first-year students from different racial and ethnic backgrounds [5-6]. This study aims to deeply investigate student-instructor interactions in a first-year chemical engineering course. The following research questions seek to supplement the investigation of the class environment by better understanding students' perspectives and how they participate and interact with the instruction in a first-year chemical engineering course asking:

1. What are students' perceptions of effective instructional and learning strategies?

2. Do students' perceptions vary by performance, achievement, or group? 
While there are other strategies to establish inclusive class environments as stated in chapter 6 of How Learning Works [11], joint-actions like student-instructor interactions have been found to be effective in improving students' motivation [12], perceptions of being successful [13], participation in class activities [9], [10], [14].

Some factors reported discouraging motivations are competitive classroom environments and grades [14]. While grades are an evaluation of student learning inferred by the instructor, students' grades have been interpreted by students as a measure of success and achievement. Students with lower performance or grades, therefore, become less motivated and doubt their abilities to be successful in the engineering program. Other educational factors reported as discouraging to students' motivation were time commitment on course tasks and the quality of teaching with large effects for female than male students [14]. Although grades reflect students' competence and indicate growing opportunities, how students interpret the grades to impact their motivation and persistence in engineering.

\section{Student Learning Framework}

Learning is an active process requiring meaningful construction of content to-be-learned and reorganizing it with one's prior knowledge [15]. Student learning can presumably be reflected in the students' performance on course assignments as each assignment is a demonstration of what students can do with the content. While poor or good performance on an assignment is indicative of learning, a single instantaneous measure of performance is unreliable in determining if learning has occurred [15]. Therefore, multiple measures of student learning are required with the accumulation of these performances resulting in the students' achievement. Student achievement defined here as the students' final grade in a course comprised of subsequent performances on course assignments. While effective instruction has been evaluated by student achievement [16], student perceptions and explanations can triangulate effective instructional practices and potentially distinguish what is and isn't working. Student performance on assignments is an evaluation of students understanding or learning which collectively compose their final grade in the course, student achievement. Student achievement has positively been correlated with class participation/engagement, diverse teaching methods, clear course goals, teacher-student rapport, class structure, and classroom environment [6], [12], [16]-[20]. The classroom environment describes the class dynamics and interactional patterns between the instructor and students which is viewed in this paper as the mode the instructor facilitates thinking and student learning.

\section{Methodology and Methods}

This study purposefully selected an introductory to chemical engineering course, process fundamentals, taught by an instructor who has been recognized for their distinguished teaching by the university. Although the studied instructor was recognized as a distinguished instructor, the award alone doesn't justify their instructional practices to be more effective than others necessarily. However, at a large research institution, an instructor recognized for distinguished teaching suggests something is salient, impactful or meaningful to some capacity in their course or instruction. While previous literature can inform the researchers of potential factors, it is argued that applying quantitative methods would oversimplify the nuances and/or relational processes, student-instructor interactions, and student perspectives. 
Multiple methods were utilized to gather evidence to identify effective instructional and learning strategies. An ethnographic approach was taken to assess explain the culture of the classroom via observations. The classroom observations served to inform the survey items while a survey was developed to capture the students' experiences. The survey contained multiple items capturing a range of student perceptions followed by semi-structured interviews to corroborate students' responses from the survey. From the survey results, students were selected based on their survey responses. The student perceptions from the survey responses would be followed up by a semistructured interview to corroborate their self-reported responses to the survey.

\section{Course Description}

The instructor is a clinical track faculty member at a large research institution. Clinical track faculty members are contracted by each department with future appointments being contingent on teaching success. The site being studied is a college level course where newly accepted discipline students must successfully complete the course before proceeding to later courses. The studied population comprised of 44 of 46 newly admitted chemical engineering students. Since the students are newly admitted into the program, they may be considered novices in discussing topics in the subject domain.

\section{Methods}

While the data analysis is ongoing, the survey questions had a 4-Likert scale to measure students' perceptions. Most survey questions utilized a 4-item Likert scale from Strongly Disagree, Disagree, Agree, to Strongly Agree. Multiple items asked students about the classrooms' environment, activities and interactions as well as self-efficacy. 42 of the 46 undergraduate chemical engineering students consented to participate in the study. A closedended survey was administered to participants with a $52 \%$ response rate.

\section{Preliminary Results}

$74 \%$ of the responding students indicated the homework and in-class worksheets were most conducive to their learning while reading the textbook was perceived by $60 \%$ of the respondents as the least effective learning strategy. All student responses agree ( $\sim 77 \%$ strongly agree) that the class was structured in a way that fostered learning which developed their problem-solving skills ( $60 \%$ strongly agree).

- in-class activities to be most in learning and understanding concepts

- the instructor structured class inviting of student participation and engaging

All of the undergraduate chemical engineering students agreed they had developed problemsolving skills from the course with $95 \%$ feeling confident in applying what they learned in the course to future chemical engineering coursework.

\section{Future work}

While multiple students were recruited, only one student agreed to participate in an interview. A semi-structured protocol was used to allow for the student to elaborate on their survey responses and learning experiences. The interview will be transcribed and holistically coded for a broad understanding of experiences. 


\section{Work Cited}

[1] "NSF Science and Engineering Indicators: 2012 - Data.gov," 2012.

[2] National Science Foundation and National Center for Science and Engineering Statistics, "Women, Minorities, and Persons with Disabilities in Science and Engineering: 2017: (558442013-001).” American Psychological Association, 2017.

[3] E. T. Pascarella and P. T. Terenzini, How college affects students: A third decade of research (Vol. 2). San Francisco: Jossey-Bass, 2005.

[4] "Framework for Evaluating Impacts of Broadening Participation Projects," 2009.

[5] S. Freeman et al., "Active learning increases student performance in science, engineering, and mathematics," Proc. Natl. Acad. Sci., vol. 111, no. 23, pp. 8410-8415, Jun. 2014.

[6] H. Pedrosa de Jesus, P. Almeida, J. J. Teixeira-Dias, and M. Watts, "Where learners' questions meet modes of teaching," Res. Educ., no. 78, p. 1, 2007.

[7] R. M. Felder, "How students learn: adapting teaching styles to learning styles," in Proceedings Frontiers in Education Conference, 1988, pp. 489-493.

[8] S. C. H. Chan, J. C. L. Wan, and S. Ko, "Interactivity, active collaborative learning, and learning performance: The moderating role of perceived fun by using personal response systems,” Int. J. Manag. Educ., vol. 17, no. 1, pp. 94-102, 2019.

[9] G. D. Kuh, T. M. Cruce, R. Shoup, J. Kinzie, and R. M. Gonyea, "Unmasking the Effects of Student Engagement on First-Year College Grades and Persistence," J. High. Educ., vol. 79, no. 5, pp. 540-563, Sep. 2008.

[10] R. M. Carini, G. D. Kuh, and S. P. Klein, "Student Engagement and Student Learning: Testing the Linkages*," Res. High. Educ., vol. 47, no. 1, pp. 1-32, Feb. 2006.

[11] S. A. Ambrose, M. W. Bridges, M. DiPietro, M. C. Lovett, M. K. Norman, and R. E. Mayer, How Learning Works: Seven Research-Based Principles for Smart Teaching.

Hoboken, UNITED STATES: John Wiley \& Sons, Incorporated, 2010.

[12] L. Anderman, C. E. Andrzejewski, and J. Allen, "How Do Teachers Support Students' Motivation and Learning in Their Classrooms?," Teach. Coll. Rec., vol. 113, no. 5, pp. 9691003, 2011.

[13] S. A. Bjorklund, J. M. Parente, and D. Sathianath, "Effects of Faculty Interaction and Feedback on Gains in Student Skills," J. Eng. Educ., vol. 93, no. 2, pp. 153-160, Apr. 2004.

[14] C. T. Amelink and P. S. Meszaros, "A comparison of educational factors promoting or discouraging the intent to remain in engineering by gender," Eur. J. Eng. Educ., vol. 36, no. 1, pp. 47-62, Mar. 2011.

[15] L. Fiorella and R. E. Mayer, "Eight Ways to Promote Generative Learning," Educ. Psychol. Rev., vol. 28, no. 4, pp. 717-741, Dec. 2016.

[16] K. Grygoryev and S. Karapetrovic, "Tracking Classroom Teaching and Learning: An SPC Application,” Qual. Eng., vol. 17, no. 3, pp. 405-418, Jul. 2005.

[17] B. Johnson-Farmer and M. Frenn, "Teaching Excellence: What Great Teachers Teach Us," YJPNU J. Prof. Nurs., vol. 25, no. 5, pp. 267-272, 2009.

[18] C. K. Vivekmetakorn and M. Thamma, "Teacher Questioning from a Discourse Perspective," LEARN J. Lang. Educ. Acquis. Res. Netw., vol. 8, no. 1, pp. 63-87, Jun. 2015.

[19] D. L. Roorda, H. M. Y. Koomen, J. L. Spilt, and F. J. Oort, "The Influence of Affective Teacher-Student Relationships on Students' School Engagement and Achievement: A MetaAnalytic Approach,” Rev. Educ. Res., vol. 81, no. 4, pp. 493-529, Dec. 2011. 
[20] R. M. Felder and J. Spurlin, "Applications, Reliability and Validity of the Index of Learning Styles,” Int. J. Eng. Educ., vol. 21, no. 1, pp. 103-112, 2005. 